\title{
Traço e estado de ansiedade de nutrizes \\ com indicadores de hipogalactia e nutrizes com galactia normal*
}

\author{
TRACE AND ANXIETY OF NURSING MOTHERS WITH INSUFFICIENT AND \\ NORMAL BREAST FEEDING INDICATORS
}

\section{TRAZO Y ESTADO DE ANSIEDAD DE MUJERES LACTANTES CON INDICADORES DE HIPOGALACTIA Y MUJERES LACTANTES CON GALACTIANORMAL}

Ilva Marico Mizumoto Aragaki ${ }^{1}$, Isília Aparecida Silva², Jair Lício Ferreira dos Santos ${ }^{3}$

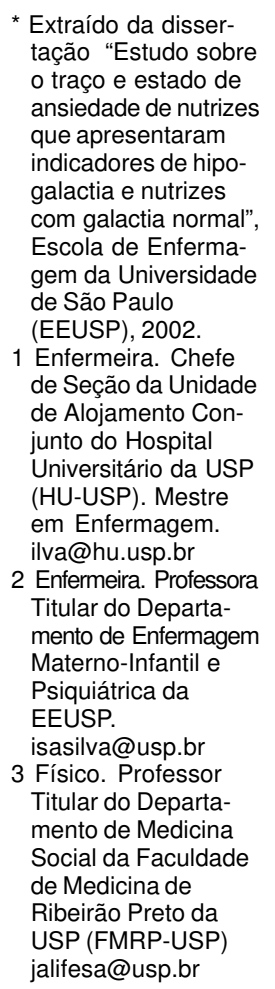

2 Enfermeira. Professora

Titular do Departamento de Enfermagem

Materno-Infantil e

Psiquiátrica da EEUSP.

isasilva@usp.br

3 Físico. Professor

Titular do Departa-

mento de Medicina

Social da Faculdade

de Medicina de

Ribeirão Preto da USP (FMRP-USP) jalifesa@usp.br

\section{RESUMO}

Este estudo objetivou identificar e comparar o traço e estado de ansiedade, no $10^{\circ}$ dia pós-parto e estado de ansiedade no $30^{\circ}$ dia puerperal, das nutrizes primíparas e multíparas que apresentaram indicadores de hipogalactia e nutrizes com galactia normal; verificar possíveis relações entre o estado de ansiedade das nutrizes nesses dois momentos com a presença dos indicadores de hipogalactia. É um estudo exploratório/descritivo, cujos dados foram obtidos com 168 nutrizes e seus filhos, por meio de entrevistas realizadas em consulta de enfermagem nos $10^{\circ}$ e $30^{\circ}$ dias pósparto. Os resultados obtidos mostraram que as primíparas e multíparas hipogalactas e as primíparas com galactia normal apresentaram traço de ansiedade mais elevado do que os estados de ansiedade por ocasião do $10^{\circ} \mathrm{e}$ $30^{\circ}$ dia pós-parto. Houve remissão dos sinais maternos de ansiedade, com o passar do tempo, que pode ter sido decorrente da correção da técnica da amamentação e apoio às nutrizes.

\section{DESCRITORES}

Transtornos da lactação.

Aleitamento materno (psicologia). Ansiedade.

\section{ABSTRACT}

The objective of this study was to identify and compare the trace and the anxiety state on the $10^{\text {th }}$ day postpartum and the anxiety state on the $30^{\text {th }}$ day postpartum of primiparous and multiparous nursing mothers who present insufficient breast feeding indicators and nursing mothers with normal breast feeding, in order to verify the possible relationships between the anxiety state of the nursing mothers in those two moments with the insufficient breast feeding indicators presented. This is an exploratory and descriptive study, whose data has been gotten from 168 nursing mothers and their children by means of interviews in nursing consultations in the 10 th and $30^{\text {th }}$ day postpartum. The results obtained showed that primiparous and multiparous with insufficient breast feeding and primiparous with normal lactation presented higher anxiety state trace than the anxiety state on the $10^{\text {th }}$ and $30^{\text {th }}$ day postpartum. There was remission of the maternal signals of anxiety with the passing of time, which may be caused by the correction of the breast feeding technique and support to the nursing mothers.

\section{KEY WORDS}

Lactation disorders.

Breast feeding (psychology). Anxiety.

\section{RESUMEN}

Este estudio tuvo por objetivo identificar y comparar el trazo y estado de ansiedad, en el $10^{\circ}$ dia post parto y estado de ansiedad en el $30^{\circ}$ dia puerperal, de las mujeres lactantes primíparas y multíparas que presentaron indicadores de hipogalactia y mujeres lactantes con galactia normal; verificar posibles relaciones entre el estado de ansiedad de las mujeres lactantes en esos dos momentos con la presencia de los indicadores de hipogalactia. Es un estudio exploratorio/descriptivo, cuyos datos fueron obtenidos con 168 mujeres lactantes y sus hijos, por medio de entrevistas realizadas en consulta de enfermería en $\operatorname{los} 10^{\circ}$ y $30^{\circ}$ días después del parto. Los resultados obtenidos mostraron que las primíparas y multíparas hipogalactas y las primíparas con galactia normal presentaron trazo de ansiedad más elevado que los estados de ansiedad en el $10^{\circ}$ y $30^{\circ}$ dia post parto. Hubo remisión de las señales maternas de ansiedad, con el pasar del tiempo, que puede haber sido consecuencia de la corrección de la técnica de amamantamiento y apoyo a las mujeres lactantes.

\section{DESCRIPTORES}

Trastornos de la lactancia. Lactancia materna (psicología). Ansiedad. 


\section{INTRODUÇÃO}

A importância da amamentação e, ao mesmo tempo, os baixos índices de sua prática em nossa sociedade, têm sido considerados, tanto pelo meio acadêmico, como pelas redes assistenciais de saúde, como uma contradição. Essa situação reside, no fato da prática da amamentação ser um processo multifatorial, que deve integrar-se a inúmeros elementos presentes na vida da mulher, da criança, da família, não atendendo meramente ao apelo da natureza de ser mãe $e^{(1)}$.

Entre as causas de desmame precoce, está a preocupação com o volume de leite produzido. Quando a quantidade de leite é considerada insuficiente pela mulher, traz uma série de dificuldades para a continuidade da amamentação ${ }^{(2)}$.

Atuando na unidade de Alojamento Conjunto durante catorze anos, deparo com mulheres que apresentam a queixa da hipogalactia. Apesar de saber que a apojadura acontece por volta de até setenta e duas horas após o parto, observo que em alguns casos a quantidade de colostro é pouquíssima ou até mesmo ausente, gerando no profissional a necessidade de compreender as manifestações de ansiedade materna que ocorrem nestas situações, e conseguir lidar com elas.

Segundo documentos publicados pela Organização Mundial da Saúde-OMS ${ }^{(3)}$, ter pouco leite é a causa mais alegada pelas mulheres para o desmame precoce. No entanto, sabe-se que o mito do pouco leite, biologicamente só se explica, quando este fenômeno está associado a distúrbios hormonais ou estruturais da mama, ou ainda, a estados de ansiedade ou estresse. $\mathrm{Na}$ maioria das vezes, esta é uma resposta ou justificativa apresentada pela mulher para explicar o desmame de uma forma que a sociedade aceite sem questionamentos.

Por outro lado, é preciso estar atento às razões alegadas pelas mulheres, pois estas vivenciam a amamentação, sofrendo uma série de interferências de seu contexto, o que muitas vezes, por falta de conhecimento ou por exposição a situações estressantes, podem acreditar, de fato, que não são capazes de produzir leite em quantidade suficiente para nutrição do filho. Dessa forma, a hipogalactia, seja real ou interpretação materna equivocada, é um fenômeno com o qual mães e profissionais têm-se deparado no processo da amamentação e que configura em um dos grandes desafios para a assistência em aleitamento materno.

Na prática cotidiana de manejo da amamentação observa-se que, na maioria das situações em que ocorre a referência materna de "pouco leite", é possível o profissional estabelecer algum tipo de intervenção eficaz, o mais precoce possível, restabelecendo uma produção adequada de leite, ou a minimização da intranqüilidade materna.
No entanto, os aspectos emocionais maternos configuram-se naqueles mais difíceis de serem identificados e abordados pela equipe de saúde, junto à nutriz. A ansiedade é um estado emocional com componentes psicológicos e fisiológicos, que faz parte do espectro normal das experiências humanas, sendo propulsora do desempenho das atividades do indivíduo ${ }^{(4)}$.

Procurando elucidar a relação entre o mecanismo da ansiedade e a "ejeção pobre" de leite com conseqüente interpretação de hipogalactia, encontramos a afirmação de que o reflexo de liberação do leite pode ser suprimido pelos efeitos adrenérgicos produzidos na reação de alarme ${ }^{(5)}$. Assim, se a mulher ficar nervosa ou ansiosa durante a mamada, seu leite continuará a ser produzido, mas não drenará facilmente, intensificando assim, sua ansiedade e frustração.

Embora todos esses elementos, de origem biológica ou subjetiva, sejam apontados como interferentes no processo da amamentação e mais especificamente, causadores da inibição da lactação, ainda não há evidências muito claras sobre a relação que se estabelece entre os níveis de ansiedade e a ocorrência da hipogalactia. As pesquisas que abordam o assunto, versam sobre quadros de hipogalactia causada por patologias maternas ou por quadros clínicos que impedem a suç̧ão direta do $\mathrm{RN}$ ao peito materno, o que implica a necessidade de estudarmos a questão com mulheres e crianças sadias vivenciando o processo de amamentação.

$\mathrm{Na}$ prática assistencial do manejo da amamentação, o conhecimento dessa relação torna-se cada vez mais importante, frente ao descompasso entre a evolução das técnicas de promoção da amamentação e elementos de suporte e apoio à mulher que vivencia o processo. Dessa forma, os profissionais de saúde, por sua vez, têm a responsabilidade de construir bases de conhecimento para lidar com a questão da hipogalactia. Poucas têm sido as pesquisas que trabalham com essa questão. Assim, na oportunidade desse estudo, busco elucidar algumas questões relativas à hipogalactia referida pelas mulheres, com as quais convivo no cotidiano do meu exercício de prestar assistência à puérpera/nutriz.

\section{OBJETIVOS}

1. identificar o traço e estado de ansiedade no $10^{\circ}$ dia pósparto e estado de ansiedade no $30^{\circ}$ dia pós-parto das nutrizes primíparas e multíparas que apresentam indicadores de hipogalactia;

2. caracterizar o traço e estado de ansiedade no $10^{\circ}$ dia pósparto e estado de ansiedade no $30^{\circ}$ dia pós-parto das nutrizes primíparas e multíparas que apresentam galactia normal; 
3. comparar o traço e estado de ansiedade das nutrizes hipo e normogalactas ${ }^{(a)}$, no $10^{\circ}$ dia e no $30^{\circ}$ dia pós-parto;

4. verificar as possíveis relações entre o estado de ansiedade das nutrizes no $10^{\circ}$ e no $30^{\circ}$ dia pós-parto com os indicadores de hipogalactia apresentados por elas ou seus filhos.

\section{MÉTODO}

O estudo do tipo exploratório/descritivo foi realizado no Hospital Universitário da Universidade de São Paulo - HUUSP, que conta com a unidade de Alojamento Conjunto (AC) para atendimento à puérpera e ao recém-nascido $(\mathrm{RN})$. $\mathrm{O}$ tipo de alimentação do RN é leite materno em livre demanda. A permanência de ambos na unidade compreende 60 horas pós-parto, desde que não ocorra nenhuma intercorrência materna ou infantil. Após a alta hospitalar, por volta do $10^{\circ}$ dia pós-parto, mãe e filho retornam para uma Consulta de Enfermagem, ocorrendo a intervenção da enfermagem frente a qualquer necessidade ou anormalidade apresentada pela mãe ou pelo filho.

Fizeram parte deste estudo, 168 puérperas e seus filhos nascidos no $\mathrm{HU}$ e atendidos na Consulta de Enfermagem daquele serviço, correspondente ao $10^{\circ}$ e $30^{\circ}$ dias pós-parto, nos meses de dezembro de 2000 a abril de 2001, distribuídas em 4 sub-grupos, com primíparas e multíparas hipogalactas e primíparas e multíparas normogalactas, com 42 mulheres em cada um. A consulta do $30^{\circ}$ dia foi marcada exclusivamente para este estudo.

Como critérios para inclusão no estudo, consideramos as mulheres que não apresentaram intercorrências clínicas ou obstétricas no Pré-natal, com feto único, cujo RN era de termo, sadio, Apgar maior que 7 no quinto minuto de vida e que permaneceu com a mãe no AC durante o período de internação. Estas mulheres foram divididas em duas categorias - as hipogalactas, que apresentaram queixas indicativas de hipogalactia no momento da consulta de enfermagem realizada no $10^{\circ}$ pós-parto, e as demais com galactia normal, normogalactas.

A coleta de dados para este estudo contou com a colaboração de enfermeiras do AC. Para que fosse possível obtermos consenso nos elementos a serem observados e registrados, as enfermeiras receberam orientações e esclarecimentos acerca do estudo, finalidades e objetivos, bem como, um treinamento quanto à avaliação da drenagem láctea considerando a classificação adotada neste trabalho.

As puérperas que apresentaram características para inclusão no estudo, eram abordadas pela enfermeira/ou pes-

(a) hipogalactas - termo utilizado neste estudo para denominar as mulheres que apresentaram indicadores de hipogalactia.

normogalactas - termo utilizado neste estudo para denominar as mulheres com galactia normal. quisadora, ao término da consulta de enfermagem, realizada no $10^{\circ}$ dia pós-parto. As demais puérperas que compuseram o grupo de nutrizes normogalactas foram incluídas no estudo, conforme a ordem de comparecimento à consulta, atendimento aos critérios de inclusão e aceitação destas em participar da pesquisa. Para a obtenção dos dados utilizamos três instrumentos, sendo o primeiro deles um formulário com dados de identificação da mãe e do RN reportados do prontuário, entrevista aplicada à puérpera com questões sobre história pregressa em relação à amamentação, seu conhecimento sobre técnica e processo da amamentação e dados obtidos a partir do exame físico da nutriz com a finalidade de se observar as condições das mamas, mamilos e características da drenagem láctea. Os outros dois instrumentos destinaram-se à avaliação do traço e estado de ansiedade. Para esta finalidade utilizamos o Inventário de Ansiedade TraçoEstado $^{(6)}$ do qual a escala A-traço, que avalia traço de ansiedade, foi aplicada no $10^{\circ}$ dia pós-parto, e a escala A-estado, que avalia estado de ansiedade, foi aplicada no $10^{\circ}$ e no $30^{\circ}$ dia do puerpério. Para determinação do grau de ansiedade foi adotada a categorização utilizada em um estudo sobre estresse e trabalho do enfermeiro ${ }^{(7)}$, sendo: a) 20 a 40 pontos - baixa ansiedade, b) 40 a 60 pontos - média ansiedade e c) 60 a 80 pontos - alta ansiedade.

Esta pesquisa foi aprovada pelo Comitê de Ética em Pesquisa (CEP) do HU-USP e foram adotados os procedimentos éticos com as mulheres participantes. Todas as mulheres, ao serem convidadas a participar do estudo, foram esclarecidas quanto à finalidade da pesquisa e esclarecidas do direito de participarem ou não, e que sua recusa não implicaria em prejuízo para seus atendimentos e de seus filhos. Após, foi solicitada a assinatura do documento Consentimento livre e esclarecido.

Pela natureza das variáveis em estudo foram utilizados testes não paramétricos: a) Prova de Kruskal-Wallis para mais de dois grupos independentes ${ }^{(8)}$, b) Prova da igualdade de duas distribuições pelo qui-quadrado ${ }^{(8)}$ e c) Teste exato de Fisher para duas proporções ${ }^{(9)}$. As proporções de interesse para o estudo foram comparadas pelas provas paramétricas para dois grupos ${ }^{(8)}$. Para todos os testes adotou-se como probabilidade de ocorrência do erro de primeira espécie (alfa) o nível de $5 \%$.

\section{Indicadores de Hipogalactia}

1. Por parte materna: volume de leite reduzido e reflexo de ocitocina ausente que corresponde a ausência de saída de leite no momento de sucção do RN: a) Drenagem láctea ausente - quando a expressão manual não se observar drenagem de leite, b) Drenagem láctea em pouca quantidade - quando a expressão manual se observar volume de leite, porém a quantidade é mínima que não chega a pingar e c) Drenagem láctea em média quantidade - quando a expressão manual se observar drenagem láctea em quantidade su- 
ficiente a pingar e escorrer, e à realização da ordenha manual não for possível ordenhar quantidade de leite superior a $10 \mathrm{ml}$.

Todas estas situações foram consideradas como indicadores de hipogalactia materna. Cabe ressaltar que foi considerada drenagem láctea em boa quantidade - quando a expressão manual se observar drenagem láctea em quantidade suficiente a escorrer e a esguichar e à realização da ordenha mamária for possível obter quantidade de leite superior a $10 \mathrm{ml}$, não sendo assim, considerado um indicador de hipogalactia.

2. Por parte do RN: choro excessivo e persistente após as mamadas e após realização de medidas de conforto (verificação da adequação de roupas ao ambiente, temperatura, higiene, medidas de alívio de cólicas); necessidade de complementação das mamadas referida pela mãe; ganho ponderal insuficiente (inferior a 20 gramas por dia) e frequiência de micções inferior a 6 vezes ao dia, concentrada (de cor amarela e com odor forte).

Para a classificação da gradação da hipogalactia foram considerados os indicadores relatados ou apresentados pela nutriz e RN, ou por cada um deles em separado. Sendo: hipogalactia leve - se estiverem presentes apenas um ou dois indicadores de hipogalactia, hipogalactia moderadase estiverem presentes três ou quatro indicadores de hipogalactia, hipogalactia grave - se estiverem presentes os cinco indicadores de hipogalactia e hipogalactia inexistente - ou seja, galactia normal quando não estiver presente nenhum indicador de hipogalactia.

\section{RESULTADOS E DISCUSSÃO}

As 168 mulheres deste estudo foram distribuídas em quatro sub-grupos, compostas por 42 primíparas e 42 multíparas hipogalactas; 42 primíparas e 42 multíparas normogalactas. Conforme a presença dos indicadores de hipogalactia apresentados, as nutrizes foram divididas em nutrizes com hipogalactia leve e moderada, não tendo sido encontrado nenhum caso de hipogalactia grave.

A maioria das primíparas hipo e normogalactas encontravam-se na faixa etária entre 14 e 20 anos, correspondendo a $19(45,4 \%)$ e $18(42,8 \%)$ mulheres, respectivamente, não havendo diferença estatisticamente significativa entre as nutrizes desse grupo para a variável idade.

Foi encontrado um número maior de multíparas hipogalactas na faixa dos 28 a 34 anos, (17 ou 40,5\%) e a maioria das multíparas normogalactas se situou na faixa dos 21 a 27 anos, perfazendo um total de $22(52,4 \%)$, sendo que entre estas, encontramos diferença estatisticamente significativa para a idade (Tabela 1).

Tabela 1 - Distribuição das nutrizes quanto ao tipo de galactia, paridade e a idade - São Paulo - 2001

\begin{tabular}{|c|c|c|c|c|c|c|c|c|c|c|c|c|}
\hline \multicolumn{13}{|c|}{ Nutrizes } \\
\hline \multirow[t]{3}{*}{ Idade(anos) } & \multicolumn{6}{|c|}{ Hipogalactas } & \multicolumn{6}{|c|}{ Normogalactas } \\
\hline & \multicolumn{2}{|c|}{ Primíparas } & \multicolumn{2}{|c|}{ Multíparas } & \multicolumn{2}{|c|}{ Total } & \multicolumn{2}{|c|}{ Primíparas } & \multicolumn{2}{|c|}{ Multíparas } & \multicolumn{2}{|c|}{ Total } \\
\hline & $\mathbf{n}$ & $\%$ & $\mathbf{n}$ & $\%$ & $\mathbf{n}$ & $\%$ & $\mathbf{n}$ & $\%$ & $\mathrm{n}$ & $\%$ & $\mathrm{n}$ & $\%$ \\
\hline $14-20$ & 19 & 45,4 & 7 & 16,7 & 26 & 30,9 & 18 & 42,8 & 5 & 11,9 & 23 & 27,4 \\
\hline $21-27$ & 12 & 28,6 & 9 & 21,4 & 21 & 25,0 & 12 & 28,6 & 22 & 52,4 & 34 & 40,5 \\
\hline $28-34$ & 8 & 19,0 & 17 & 40,5 & 25 & 29,8 & 10 & 23,8 & 7 & 16,6 & 17 & 20,2 \\
\hline $35-44$ & 3 & 7,0 & 9 & 21,4 & 12 & 14,3 & 2 & 4,8 & 8 & 19,1 & 10 & 11,9 \\
\hline Total & 42 & 100 & 42 & 100 & 42 & 100 & 42 & 100 & 42 & 100 & 42 & 100 \\
\hline Qui-quadrado obs & 0,45 & & & & & Qui-qua & rado $\mathrm{cr}$ & $\mathrm{co}=7,82$ & & & & \\
\hline Qui-quadrado obs & $=10,01$ & & & & & Qui-qua & rado cr & $\mathrm{co}=7,82$ & & & & \\
\hline
\end{tabular}

Na literatura não encontramos trabalhos que tratem da questão relativa a idade das mulheres e hipogalactia, neste estudo a ocorrência de hipogalactia para as mulheres multíparas foi maior na faixa dos 28 a 34 anos, período em que podemos considerar que as mulheres estão mais maduras e mais experientes, com a expectativa de melhor sucesso na amamentação também por já terem tido experiência anterior, diferentemente das nutrizes primíparas.
No que se refere ao sexo dos RN, houve predomínio de crianças do sexo masculino em ambos os grupos hipo e normogalactas. No entanto, verifica-se uma diferença estatisticamente significante quando comparamos as nutrizes primíparas, uma vez que, destas 27 (64,3\%) primíparas hipogalactas tiveram filhos do sexo masculino e o número de primíparas normogalactas com $\mathrm{RN}$ do sexo masculino foi de $18(42,9 \%)$ de acordo com a Tabela 2. 
Tabela 2 - Distribuição das nutrizes quanto ao tipo de galactia, paridade e o sexo do RN - São Paulo - 2001

\begin{tabular}{|c|c|c|c|c|c|c|c|c|c|c|c|c|}
\hline \multicolumn{13}{|c|}{ Nutrizes } \\
\hline \multirow[t]{3}{*}{ Sexo do RN } & \multicolumn{6}{|c|}{ Hipogalactas } & \multicolumn{6}{|c|}{ Normogalactas } \\
\hline & \multicolumn{2}{|c|}{ Primíparas } & \multicolumn{2}{|c|}{ Multíparas } & \multicolumn{2}{|c|}{ Total } & \multicolumn{2}{|c|}{ Primíparas } & \multicolumn{2}{|c|}{ Multíparas } & \multicolumn{2}{|c|}{ Total } \\
\hline & $\mathbf{n}$ & $\%$ & $\mathbf{n}$ & $\%$ & $\mathbf{n}$ & $\%$ & $\mathrm{n}$ & $\%$ & $\mathbf{n}$ & $\%$ & $\mathrm{n}$ & $\%$ \\
\hline Masculino & 27 & 64,3 & 23 & 54,8 & 50 & 59,5 & 18 & 42,9 & 27 & 64,3 & 45 & 53,6 \\
\hline Feminino & 15 & 35,7 & 19 & 45,2 & 34 & 40,5 & 24 & 57,1 & 15 & 35,7 & 39 & 46,4 \\
\hline Total & 42 & 100 & 42 & 100 & 42 & 100 & 42 & 100 & 42 & 100 & 42 & 100 \\
\hline
\end{tabular}

Fisher para as primíparas $-\mathrm{P}=0,039$

Fisher para as multíparas $-\mathrm{P}=0,52$

Embora não haja evidência científica acerca dessa questão, freqüentemente, é relatado pelas nutrizes que os RN do sexo masculino, em geral, mamam com maior freqüência e requisitam maior volume de leite, assim como apresentam maior força de sucção. Isto, muitas vezes, leva a mãe a antever dificuldades para garantir a saciedade do RN exclusivamente com leite materno.

\section{Avaliação do traço, estado e grau de ansiedade das nutrizes}

Os dados do Gráfico 1 revelam que não foram encontradas diferenças estatísticas significativas entre os grupos de nutrizes hipo e normogalactas para o traço de ansiedade. Todas as nutrizes do estudo apresentaram escores de traço de ansiedade que indicam média ansiedade, o que nos sugere que estas apresentaram a mesma vulnerabilidade frente a elementos que poderiam causar ansiedade.

As nutrizes com traço de maior nível de ansiedade são as multíparas hipogalactas com a média dos escores igual a 43,9 pontos.
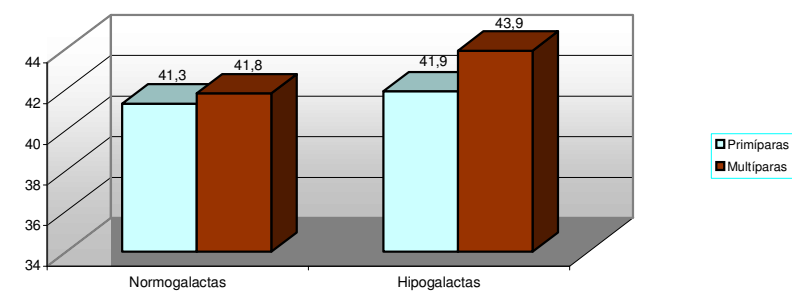

Teste de Kruskall-Wallis $\quad \mathrm{H}=2,42$

$\mathrm{H}=$ valor do qui-quadrado

Valor crítico $=7,82$ (qui-quadrado, 3 g.l., 5\%) ${ }^{(8)}$

Valor da probabilidade do qui-quadrado observado $=0,49$

Gráfico 1 - Média dos escores do traço de ansiedade das nutrizes normogalactas e das que apresentaram indicadores de hipogalactia, obtidas no $10^{\circ}$ dia pós-parto - São Paulo - 2001
A média dos escores do estado de ansiedade das nutrizes no $10^{\circ}$ dia pós-parto indica que estas, em média, mantém-se em níveis considerados de baixa ansiedade. Não houve diferença estatística significativa entre os grupos.

No entanto, chama a atenção que a maior média de escores apresentado foi pelas multíparas hipogalactas $(39,9)$, seguidas pelas primíparas normogalactas, $(39,6)$. Os valores médios dos escores para estado de ansiedade neste período foram inferiores aos obtidos para o traço de ansiedade dessas mulheres, o que nos leva a inferir que as nutrizes, por volta do $10^{\circ}$ dia pós-parto, já estão superando as dificuldades encontradas nessa primeira semana de adaptação ao filho e família.

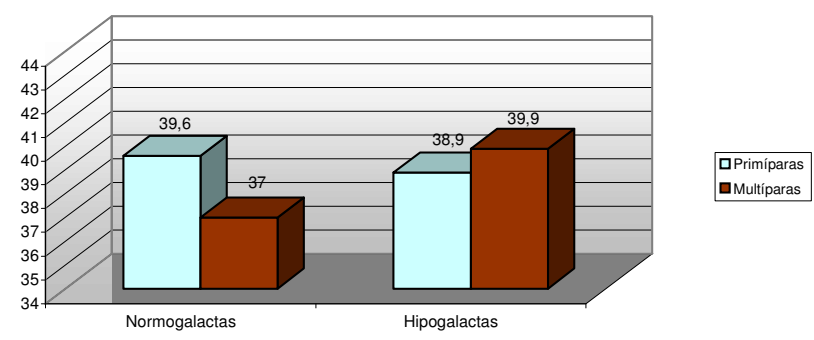

Teste de Kruskall-Wallis $\quad \mathrm{H}=3,40$

$\mathrm{H}=$ valor do qui-quadrado

Valor crítico $=7,82$ (qui-quadrado, 3 g.l., $5 \%)^{(8)}$

Valor da probabilidade do qui-quadrado observado $=0,33$

Gráfico 2 - Média dos escores do estado de ansiedade no $10^{\circ}$ dia pós-parto das nutrizes normogalactas e das que apresentaram indicadores de hipogalactia - São Paulo - 2001

Os dados do Gráfico 3 traz a média dos escores do estado de ansiedade no $30^{\circ}$ dia pós-parto das nutrizes hipo e normogalactas cujos valores ficaram entre 38,5 e 35,6 pontos, caracterizando-as como nutrizes com baixa ansiedade neste período e observamos que não houve diferença estatisticamente significativa entre elas.

Embora os valores desses escores sejam menores que os apresentados pelas nutrizes no $10^{\circ}$ dia pós-parto, cons- 
tatamos que as multíparas hipogalactas ainda apresentamse com a maior média de níveis de ansiedade, expressa pela média dos escores igual a 38,5 pontos. Embora não haja diferença estatisticamente, observa-se que as menores médias dos escores do estado de ansiedade são apresentados pelas nutrizes normogalactas, 35,6 e a 35,9 pontos para primípara e multípara, respectivamente.

Verificamos que as nutrizes, de uma forma geral, apresentaram-se menos ansiosas no $30^{\circ}$ dia pós-parto em relação ao $10^{\circ}$ dia pós-parto. Podemos inferir que isto se deve ao fato de que no $30^{\circ}$ dia pós-parto, as dificuldades encontradas foram praticamente solucionadas, o que pode ser particularmente considerado para as mulheres normogalactas que apresentaram maior diminuição dos escores.

As multíparas hipogalactas apresentaram a maior média de escores de estado de ansiedade em ambos os períodos de avaliação, embora em níveis bem próximos das primíparas. Tal fato, talvez não esteja associado diretamente com a amamentação e sim a outros problemas relatados pelas mesmas, como a preocupação com os outros filhos e doenças na família.

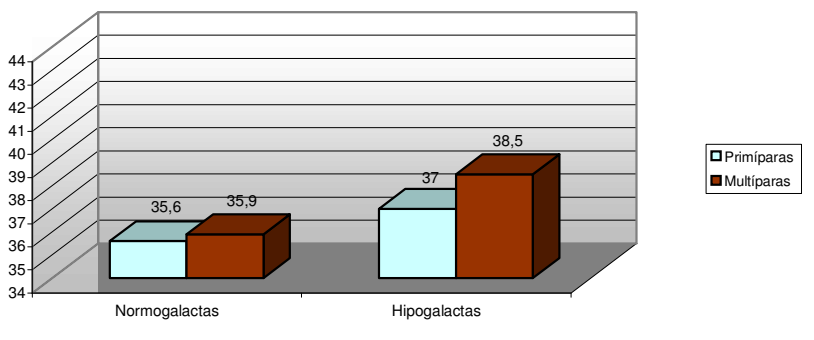

Teste de Kruskall-Wallis $\quad \mathrm{H}=4,14$ $\mathrm{H}=$ valor do qui-quadrado

Valor crítico $=7,82$ (qui-quadrado, 3 g.l., $5 \%)^{(8)}$

Valor da probabilidade do qui-quadrado observado $=0,25$

Gráfico 3 - Média dos escores do estado de ansiedade no $30^{\circ}$ dia pós-parto das nutrizes normogalactas e das que apresentaram indicadores de hipogalactia. São Paulo - 2001

Quanto às relações encontradas entre os estados de ansiedade e os indicadores de hipogalactia apresentados pela mãe ou seu filho, houve associação entre bom volume de leite drenado e baixa ansiedade por ocasião do $10^{\circ}$ dia pós-parto, correspondendo a $14(33,3 \%)$ primíparas e 15 $(35,7 \%)$ multíparas. Esta associação é significativa ao nível de 5,07\% pelo teste exato de Fisher ${ }^{(9)}$. No $30^{\circ}$ dia pós-parto, ocorreu um aumento do número de mulheres que apresentavam esta associação, boa drenagem de volume lácteo e escores de baixo nível de ansiedade, $19(45,23 \%)$ e $15(35,71 \%)$, respectivamente. Esta associação não é significativa ao nível 5\% (adotado neste estudo) segundo o teste exato de Fisher ${ }^{(9)}$. Entretanto pela proximidade do valor observado no teste $(6,6 \%)$ pode-se aceitar a existência de uma tendência para a associação. Podemos inferir que é esperada uma diminuição da gradação da ansiedade das nutrizes do $10^{\circ}$ dia pós-parto para o $30^{\circ}$ dia pós-parto, pois nesta ocasião, as nutrizes já estão mais habituadas com o seu novo papel de mãe como cuidadora do RN e muitas das questões de adaptação, em especial com os cuidados do RN já estão sendo solucionados, como foi encontrado em estudo anterior realizado na mesma instituição ${ }^{(10)}$.

Uma das queixas freqüentes das nutrizes e que as levam a pensar ou interpretar seu volume de leite como insuficiente, é a persistência do choro do RN após as mamadas. Ao menor sinal de que a produção de leite não atende a demanda da criança, caracterizada por choro e vigília, a nutriz sente-se insegura, podendo elevar os níveis de ansiedade, que por sua vez pode acarretar alterações na fisiologia da lactação, incorrendo na possibilidade real da diminuição da produção láctea $^{(1)}$. As multíparas hipogalactas foram as que mais se referiram ao choro persistente do RN após as mamadas, por ocasião do $10^{\circ}$ dia pós-parto, 24 ou $57,1 \%$. Entre elas, a maioria, apresentava escores para estado de média ansiedade, 17 (40,5\%), o mesmo ocorrendo com as primíparas hipogalactas que tinham a mesma observação sobre o filho, $17(40,5 \%)$. No $30^{\circ}$ dia pós-parto, houve mudança desse quadro, com relação às manifestações do RN e estado de ansiedade materna. Foi observado um aumento no número de nutrizes que indicavam comportamento calmo do RN, e que também apresentavam escores de baixa ansiedade, sendo $24(57,14 \%)$ primíparas e $18(42,86 \%)$ multíparas.

Percebemos a importância que o comportamento da criança exerce sobre o estado de ansiedade materna, mas questionamos por outro lado, se são as mães ansiosas que transmitem ansiedade para as crianças que ficam mais agitadas ocorrendo assim, um círculo vicioso.

Quanto ao ganho ponderal e os estados de ansiedade, o maior número de $\mathrm{RN}$ com ganho ponderal inferior a 20 gramas por dia, por ocasião do $10^{\circ}$ dia pós-parto eram filhos de primíparas, $28(66,6 \%)$ e entre eles, a maioria, 18 (64,3\%), tinham mães que apresentaram escores para estado de média ansiedade, enquanto que a maioria dos $\mathrm{RN}$ de multíparas tiveram um ganho de peso adequado, para este período 24 $(57,1 \%)$, observando-se que entre essas, havia um maior número de mulheres, $13(54,2 \%)$ que tinham escores para estado de baixa ansiedade.

No decorrer do primeiro mês de amamentação, não encontramos associação significativa entre a curva ponderal do RN e estados de ansiedade materna, uma vez que todos os lactentes aos 30 dias haviam ganhado peso esperado para a idade, independente do escore de ansiedade expresso pela mãe.

Todos os RN do estudo apresentaram eliminações urinárias em quantidade superior a 6 vezes ao dia, de modo que esta variável não constituiu em um indicativo de hipogalactia. 


\section{Gradação de drenagem láctea}

No $10^{\circ}$ dia pós-parto, 26 ou $61,9 \%$ das primíparas hipogalactas apresentaram hipogalactia leve, isto é, a mãe ou RN apresentava um ou dois indicadores de hipogalactia e 16 ou $38,1 \%$ apresentaram hipogalactia moderada, ou seja, a mãe ou RN apresentava três ou quatro indicadores de hipogalactia. No $30^{\circ}$ dia pós-parto, o número de primíparas com hipogalactia leve diminuiu para 20 ou $47,6 \%$ e para 8 ou $19,1 \%$ aquelas com hipogalactia moderada e 14 ou $33,3 \%$ apresentavam hipogalactia inexistente, isto é, deixaram de apresentar indicador de hipogalactia.

As multíparas hipogalactas também apresentaram diminuição da gradação da hipogalactia, no decorrer da amamentação sendo encontradas no $10^{\circ}$ dia pós-parto, 23 ou $54,8 \%$ nutrizes com hipogalactia leve e 19 ou $45,2 \%$ nutrizes com hipogalactia moderada. No $30^{\circ}$ dia pós-parto esse número caiu para 16 ou $38,1 \%$ nutrizes com hipogalactia leve, 14 ou 33,3\% com hipogalactia moderada e 12 ou $28,5 \%$ delas também não relatavam mais indicadores de hipogalactia.

Tal fato pode ser explicado pela intervenção da enfermeira na Consulta de Enfermagem, no $10^{\circ}$ dia pós-parto em que ocorreu a correção da técnica da amamentação, sendo as nutrizes orientadas quanto as importância de estarem despertando os RN que se apresentavam sonolentos, da oferta do leite posterior e outras orientações relativas a amamentação.

\section{CONCLUSÕESE CONSIDERAÇÕES FINAIS}

- Quanto ao traço de ansiedade, as primíparas e as multíparas hipogalactas apresentaram a média dos escores indicativos de média ansiedade, correspondendo a 41,9 e 43,9 pontos, respectivamente. Quanto ao estado de ansiedade no $10^{\circ}$ dia pós-parto, a média dos escores para essas mulheres se situou em baixa ansiedade com a pontuação igual a 38,9 e 39,9. Em relação ao estado de ansiedade no $30^{\circ}$ dia pós-parto, mais uma vez, a média dos escores indicou baixa ansiedade, com a pontuação igual a 37 e 38,5, na mesma ordem.

- As primíparas e multíparas normogalactas apresentaram a média dos escores de traço de ansiedade correspondentes à média ansiedade. No que concerne ao estado de ansiedade por ocasião do $10^{\circ}$ e $30^{\circ}$ dia pós-parto, a média dos escores indicou nutrizes com baixa ansiedade.

- Quando comparamos os grupos, podemos dizer que embora todas tenham apresentado escores para traço, que as situe na categoria de média ansiedade, foram as multíparas hipogalactas que apresentaram média mais alta para este item, seguidas das primíparas do mesmo grupo. Também foram essas nutrizes que atingiram médias mais elevadas dos escores de estado de ansiedade em ambos os períodos avaliados, mesmo que as médias obtidas tenham indicado níveis de baixa ansiedade.

- Quanto às relações encontradas entre os estados de ansiedade e os indicadores de hipogalactia apresentados pela mãe ou seu filho, no $10^{\circ}$ dia pós-parto, a maioria das nutrizes, tanto primíparas como multíparas, apresentou bom volume de leite drenado e escores que indicavam baixa ansiedade. No $30^{\circ}$ dia pós-parto, houve um aumento do número dessa associação, boa drenagem láctea e escores para baixo nível de ansiedade.

- As multíparas hipogalactas foram as que mais se referiram ao choro persistente do $\mathrm{RN}$ após as mamadas, no $10^{\circ}$ dia pós-parto e a maioria, apresentava escores para média ansiedade. No $30^{\circ}$ dia pós-parto, houve mudança desse quadro, os RN se tornaram mais calmos e as mães menos ansiosas.

- No que concerne ao peso o maior número de $\mathrm{RN}$ com ganho ponderal inferior a 20 gramas por dia, por ocasião do $10^{\circ}$ dia pós-parto, eram filhos de primíparas e a maioria das mães apresentaram escores para estado de média ansiedade, enquanto que a maioria dos $\mathrm{RN}$ de multíparas tiveram um ganho de peso adequado, para este período, observando-se que entre essas, havia um maior número de mulheres com escores para estado de baixa ansiedade.

- No decorrer do primeiro mês de amamentação, não encontramos associação significativa entre a curva ponderal do RN e estados de ansiedade materna, uma vez que todos os lactentes aos 30 dias haviam ganhado peso esperado para a idade, independente do escore de ansiedade expresso pela mãe.

- A maior parte das primíparas que apresentaram hipogalactia leve estavam associadas a escores de baixa ansiedade por ocasião do $10^{\circ}$ dia pós-parto, sendo este número menor para as multíparas com a mesma associação. No $30^{\circ}$ dia pós-parto, a maior parte das primíparas hipogalactas que apresentou hipogalactia leve também estava associada a escores de baixa ansiedade. Esse número representa um percentual menor de mulheres com esta associação, que também apresentou discreta diminuição para as multíparas devido ao fato do aumento do número de mulheres que não apresentavam mais indicadores de hipogalactia, condição esta que se mostrou independente de estado de ansiedade apresentado pelas nutrizes.

A realização deste estudo procurou contribuir para a elucidação sobre um dos aspectos considerados interferentes no decorrer da amamentação, que é hipogalactia associada à ansiedade materna, pelo fato de não encontrarmos na literatura tal abordagem. A ausência de trabalhos nesta linha, não nos propiciou enriquecer a discussão. 
O comportamento choroso do RN, preocupação com o peso do RN, embora em diferentes e modestas proporções, neste estudo podem estar relacionados à interpretação de diminuição da produção e ejeção láctea que por sua vez aumenta o grau de ansiedade materno. Embora o desenho deste estudo, tenha utilizado a referência materna e alguns dados objetivos de avaliação de exame físico da nutriz e RN para inclusão destas mulheres na pesquisa e não apenas o dado objetivo de ausência de "drenagem láctea", salientamos a importância de considerar a informação e queixa materna que faz menção à situação em que a mulher coloca-se como hipogalacta.

Pudemos constatar, que a grande maioria das nutrizes que queixavam-se de pouca produção láctea ou outros indicadores considerados usualmente como de hipogalactia não eram compatíveis com o volume de leite ordenhado. Os resultados demonstraram, que em sua maioria, esta situação era dependente da correção da técnica de amamentação, ou da interpretação materna de inadequação de seu desempenho ou das manifestações de comportamento do RN.

\section{REFERÊNCIAS}

(1) Silva IA. Amamentar: uma questão de assumir riscos ou garantir benefícios. São Paulo: Robe; 1997.

(2) Roque GP, Marcelo MS, Suarez E La L. Factores asociados al destete precoz. Rev Cubana Med Gen Integr. 1999;(15)3: $278-84$

(3) Organização Mundial de Saúde (OMS). Alimentação infantil: bases fisiológicas. IBFAN Brasil e Instituto de Saúde, OMS, OPAS e UNICEF BRASIL; 1994. Cap. 2, p. 17-35.

(4) Andrade LHG, Gorenstein C. Aspectos gerais das escalas de avaliação de ansiedade. Rev Psiq Clín. 1998;(25)6:285-90.

(5) Rhoades RA, Tanner GA. Medical physiology. Massachusetts: Litlle Brown; 1995.

(6) Spielberger C, Gorsuch RL, Lushene RE. Inventário de ansiedade traço-estado - IDATE. Trad. de Ângela M. B. Biaggio e Luiz Natalício. Rio de Janeiro: CEPA; 1979.
A mulher espera produzir grande quantidade de leite $\mathrm{e}$ quando o volume que esta produz não atende sua expectativa, esta pode considerar-se na situação de hipogalactia, sendo uma das motivações para a introdução de alimentos na dieta do RN, como os leites heterólogos ${ }^{(1,11)}$.

Uma vez havendo orientação e informação, boa parte das questões tenderam à melhoria da qualidade da experiência da amamentação, salvo situações inerentes ao contexto materno, como necessidade de retorno ao trabalho ou influências culturais bastante arraigadas em nossa população.

Deste estudo, consideramos a importância de se oferecer acolhimento às mulheres sejam elas primíparas ou multíparas e da continuidade de acompanhamento destas após a alta hospitalar, se possível abrangendo período maior que os primeiros 10 dias de pós-parto.

Ainda, ressalta-se a necessidade de aprofundar os estudos sobre a relação entre os níveis de ansiedade materna e a hipogalactia, seja ela real ou gerada a partir da interpretação materna para a obtenção de subsídios e conseqüentemente um melhor planejamento da assistência das mulheres que apresentam estas queixas.

(7) Chaves EC. Stress e trabalho do enfermeiro: a influência de características individuais no ajustamento e tolerância ao turno noturno [tese]. São Paulo: Instituto de Psicologia da USP; 1994.

(8) Siegel S. Estatística não paramétrica. São Paulo: McGraw Hill; 1975.

(9) Berquó ES, Souza JMP, Gotlieb S. Bioestatística. São Paulo: EPU; 1980.

(10) Shimoda GT. Lesão da papila mamária: características, freqüência e fatores presentes na ocorrência desta intercorrência em um grupo de nutrizes internadas em sistema alojamentoconjunto [dissertação]. São Paulo: Escola de Enfermagem da USP; 2001.

(11) Silva IA. Enfermagem e aleitamento materno: combinando práticas seculares. Rev Esc Enferm USP. 2000;34(4):362-9. 